\title{
Um aspecto da teoria saussuriana que Jakobson teria ignorado ou da relativização do caráter radical da separação entre sincronia e diacronia em Saussure
}

\section{An aspect of saussurean theory that Jakobson would have ignored or on the relativisation of the radical character of the separation between synchrony and diachrony}

\author{
Marcio Alexandre Cruz \\ Universidade Federal de Alagoas (UFAL)
}

\begin{abstract}
RESUMO
O Curso de linguística geral foi considerado por Jakobson como uma "hipótese de trabalho". No lugar de fornecer um balanço dos avanços em linguística (como, por exemplo, Prinzipien der Sprachgeschichte de Hermann Paul), essa obra apresentaria os começos movimentados de uma perspectiva nova e inovadora. Situado entre duas diferentes maneiras de ver as coisas, ela não poderia estar totalmente isenta de contradições, e considerá-la como um compêndio poderia levar a dois erros fundamentais: 1) rejeitar em bloco seu conteúdo; 2) dissimular as contradições mais do que considerá-las como um fato instrutivo. Apesar dessa apreciação, parece que Jakobson fixa interpretações a propósito de aspectos da teoria saussuriana que o próprio Saussure reconheceu, algumas vezes de maneira explícita, como demandando ainda maiores explicações. A separação entre sincronia e diacronia é um exemplo. Este artigo procura mostrar, em particular, algumas hesitações de Saussure relativas a esse ponto completamente ignoradas por Jakobson.
\end{abstract}

PALAVRAS-CHAVE: Saussure, Jakobson, sincronia, diacronia.

\begin{abstract}
The Course in General Linguistics was considered by Jakobson as a "work hypothesis". Instead of reviewing the achievements of linguistics (such as Prinzipien der Sprachgeschichte by Hermann Paul), this book would present the turbulent beginnings of a new and innovative point of view. Situated between two different perspectives, it could not be totally free of contradictions, and considering it as a compendium may lead to two fundamental errors: 1) rejecting in block all the content of the book; 2) dissimulating the contradictions rather than consider them as an instructive fact. Despite this appreciation, it seems that Jakobson has fixed interpretations regarding aspects of saussurean theory that Saussure himself has recognized, sometimes explicitly, as calling for further explanations. The separation between synchrony and diachrony is one example. This paper aims particularly to show some Saussure's hesitations on this point that Jakobson has completely ignored.
\end{abstract}

KEYWORDS: Saussure, Jakobson, synchrony, diachrony. 


\section{INTRODUÇÃO}

Para Roman Jakobson (1896-1982), o Curso de linguística geral (CLG) é um "prólogo" e se opõe, desse modo, às "obras de síntese", isto é, aquelas obras que "fazem o balanço das pesquisas, dos resultados obtidos e dos dogmas de uma escola dada e coroam por assim dizer sua atividade, apresentando uma doutrina acabada" (JAKOBSON, [1942]1984, p. 164). É o caso, por exemplo, segundo Jakobson, de Prinzipien der Sprachgeschichte de Hermann Paul. Para o linguista russo, o CLG, ao contrário, no lugar de um edifício acabado, apresenta, antes, "os começos movimentados de uma edificação nova e inovadora" (JAKOBSON, [1942]1984, p. 164). O que constitui o Curso de linguística geral "não são, portanto, dogmas definitivos, mas hipóteses de trabalho e esboços lúcidos” (JAKOBSON, [1942]1984, p. 164). Justamente porque "essa obra se encontra situada no cruzamento de duas épocas, no limite de duas formas diferentes de ver as coisas", ela "não pode jamais estar isenta de contradições, e seria perigoso tanto quanto errôneo ver nesse Curso de linguística [...] uma espécie de compêndio, uma doutrina sólida!" (JAKOBSON, [1942]1984, p. 164) Esse erro engendraria, ainda segundo Jakobson, ou uma tentativa de dissimular suas contradições ou, ao contrário, uma tentativa de justamente ignorar seus valores fundamentais e, assim, condená-la em bloco. Ele afirma, então, quanto a ele, que não pretende de modo algum "dissimular as frequentes contradições no livro de Saussure", mas, antes, de "discerni-las sistematicamente, considerando-as como um fato dos mais instrutivos e notadamente como um traço de transição entre duas concepções linguísticas profundamente diferentes" (JAKOBSON, [1942]1984, p. 165).

Jakobson, certamente, está longe de ignorar os valores fundamentais do CLG e, assim, de condená-lo em bloco. Os diversos aspectos da teoria saussuriana não foram, todavia, considerados da mesma forma pelo autor, que, apesar de reconhecer que o CLG não poderia estar isento de contradição, não deixa de fixar interpretações a respeito de pontos que Saussure reconheceu, de forma, às vezes, explícita, como sendo obscuros, e que demandavam ainda reflexões. É o caso, por exemplo, da separação entre sincronia e diacronia de que trataremos aqui neste artigo.

O bojo da discussão que propomos desenvolver, importa observar desde já, não é propriamente a recepção do Curso de linguística geral por Jakobson, assunto já amplamente discutido por diversos autores ${ }^{1}$. Gostaríamos, antes, de mostrar simplesmente em que medida essa questão em torno da separação entre os pontos de vista sincrônico e diacrônico foi para Saussure objeto de hesitações, hesitações essas sobre as quais as fontes manuscritas certamente lançam luzes, permitindo, assim, que se apresentem de forma mais evidente, mas que podem ser claramente percebidas já no próprio $C L G$, obra na qual se baseou Jakobson. Abordaremos precisamente dois aspectos do problema em torno da separação entre ambos os pontos de vista, que, ao que tudo indica, jamais encontraram em Saussure uma solução que lhe satisfizesse e que justificasse, a seus olhos, uma publicação. O primeiro aspecto concerne ao objeto que interessa a cada um desses dois pontos de vista; essa discussão

${ }^{1}$ Cf., entre outros, De Mauro, 1972[1967]; Fontaine, 1978; Gadet, 1995; Chiss e Puech, 1999; Puech, 2005; Sériot, 1999, Milano e Flores, 2016. 
suscitará uma segunda, que diz respeito ao suposto caráter radical dessa separação e que corresponde ao segundo aspecto de que trataremos.

Antes de entrarmos nessa questão propriamente dita, procederemos, contudo, a título de revisão, a uma breve retomada da discussão em torno da recepção do CLG por Jakobson e de sua crítica à separação entre os pontos de vista sincrônico e diacrônico.

\section{O Curso de linguística geral sob o prisma de Jakobson}

Se, por um lado, é inegável que Jakobson não condena o CLG em bloco, procedendo a um real trabalho de discussão conceitual, por outro, sua leitura não deixa de ser atravessada por interesses, em razão dos quais partes importantes dessa obra são ignoradas. Essa leitura interessada não é, todavia, um traço exclusivo da leitura do CLG por Jakobson; trata-se aí, com efeito, de uma característica das recepções do CLG pelos linguistas em geral, apontada por Chiss e Puech (1999), para quem a perspectiva saussuriana teria sido menos uma teoria efetivamente aplicada, testada, integrada ou superada, do que uma ferramenta que teria permitido justificar a emergência de uma série de projetos ao longo do século XX. Foi, com efeito, sobretudo com historiadores e filólogos, a partir da segunda metade do século XX, que uma leitura menos interessada do CLG pôde, enfim, se realizar, fornecendo uma imagem bastante diferente daquela de um Saussure que teria fundado a linguista ao preço da exclusão de tantos elementos fundamentais da comunicação humana.

No caso da leitura de Jakobson e dos linguistas pertencentes ao Círculo de Linguística de Praga, o CLG foi, segundo Puech, "um texto estratégico para a 'periferia' à conquista das instituições centrais” (2005, p. 96). O centro dos estudos linguísticos, no final dos anos 1920, eram a Alemanha e a França, ambas ainda fortemente inscritas na tradição historicista. Como bem afirma Jaqueline Fontaine, "os Praguenses - poder-se-ia dizer - utilizaram Saussure contra os neogramáticos” (1978, p. 35). Segundo ela, os membros do Círculo de Praga aderiram ao ponto de vista saussuriano porque Saussure lhes permitia opor a essa tradição historicista uma linguística que tinha como objeto a língua definida como sistema de signos e, portanto, uma linguística, eminentemente sincrônica, rompendo, assim, de algum modo, com uma tradição cuja hegemonia já durava cerca de um século. Lemos, de fato, no item (b) da primeira tese do Círculo linguístico de Praga: "a melhor maneira de conhecer a essência e o caráter de uma língua é a análise sincrônica dos fatos atuais”. Contudo, a linguística sincrônica que o Círculo de Praga pratica tem pouco a ver efetivamente com o projeto que se delineia no CLG. Para Fontaine (1978, p.35), "em seu conjunto, os Praguenses menosprezaram a originalidade da reflexão saussuriana"; é que eles não procederam a uma análise efetiva desse pensamento, "limitando-se a colher nele apenas o que lhes era necessário para refutarem o que, em seu entender, devia ser refutado em Linguística, as posições dos neogramáticos”. Essa posição é igualmente sustentada por Françoise Gadet, para quem "Jakobson [...] encontrou em Saussure algo que lhe é essencial, o princípio da diferença como acesso ao sistema, que ele utilizou, tanto quanto a necessidade se lhe fez sentir, como uma máquina de guerra contra o historicismo dos neogramáticos". A autora conclui, enfim: "Saussure é utilizado sem que sua originalidade seja reconhecida de modo global e sem que a letra do texto seja sempre respeitada (GADET, 1995, p.6).

No tocante ao aspecto da reflexão saussuriana que nos interessa aqui em particular, lembrando, a separação entre sincronia e diacronia, Jakobson parece ignorar passagens do CLG que obstariam sua interpretação segundo a qual essa separação seria absoluta e, se Saussure, acertadamente, por um lado, "previa e anunciava um método novo, estrutural,

Revista do GELNE, Natal/RN, Vol. 19 - Número Especial/Dossiê: p. 248-259. 2017 
aplicável à sincronia linguística", por outro, erroneamente, "seguia o velho dogma atomista dos neogramáticos em linguística histórica” (JAKOBSON, 1973, p. 22). Por exemplo, Jakobson parece ignorar esta passagem do CLG, em que se lê o seguinte:

a cada instante ela [a linguagem] implica ao mesmo tempo um sistema estabelecido e uma evolução; a cada momento, ela é uma instituição atual e um produto do passado. Parece à primeira vista muito simples de distinguir entre sistema e sua história, entre aquilo que é e aquilo que foi; na realidade, a relação que une essas duas coisas é tão estreita que é difícil separá-las (SAUSSURE, 1972, p. 24).

Ele ignora igualmente esta outra em que se faz a seguinte pergunta: "se todos os fatos de sincronia associativa e sintagmática têm sua história, como manter a distinção absoluta entre a diacronia e a sincronia?” (SAUSSURE, 1972, p. 194), e também esta: "a verdade sincrônica parece ser a negação da verdade diacrônica e, a ver as coisas superficialmente, imagina-se que seja preciso escolher; de fato não é necessário; uma das verdades não exclui a outra" (SAUSSURE, 1972 p. 135). Essas passagens parecem, em princípio, entrar em contradição com passagens em que se afirma, de fato, o caráter absoluto da separação entre os pontos de vista sincrônico e diacrônico, como esta, por exemplo: "pouquíssimos linguistas duvidam que a intervenção do fator tempo possa causar à linguística dificuldades particulares e que ela coloca sua ciência diante de duas vias absolutamente divergentes" (SAUSSURE, 1972, p. 114); ou como esta: "a oposição entre os dois pontos de vista - sincrônico e diacrônico - é absoluta e não admite compromisso" (SAUSSURE, 1972, p. 119). Essa aparente contradição convida o leitor a questionamentos, aprofundamentos, retornos... Jakobson não condena o CLG em bloco, o que seria, segundo ele, como vimos, uma das consequências possíveis do erro de se considerar essa obra como um compêndio. Mas, no que diz respeito ao problema da separação entre sincronia e diacronia, ele não estaria justamente incorrendo na outra consequência possível, efeito desse mesmo erro, que é, segundo ele próprio, como vimos também, dissimular as contradições?

A crítica do autor sobre esse problema, como se sabe, toca dois pontos fundamentais que se relacionam de algum modo: 1) o caráter cego da mudança linguística; 2) a suposta inexistência de uma relação entre sistema e mudança em Saussure. A seguinte passagem, emblemática, de seu texto intitulado "Relations entre la science du langage et les autres sciences”, resume bem esses dois pontos:

De acordo com o Curso de Saussure, a dualidade interna, constituída pela sincronia e pela diacronia, é uma causa de dificuldades particulares para a linguística e convida a uma separação completa dos dois aspectos: pode-se estudar ou as relações existentes no interior do sistema linguístico "donde toda intervenção do tempo está excluída”; ou as mudanças sucessivas particulares sem nenhuma referência ao sistema. Em outros termos, Saussure previa e anunciava um método novo, estrutural, aplicável à sincronia linguística, mas seguia o velho dogma atomista dos neogramáticos em linguística histórica. A linguística pós-saussuriana refutou sua identificação errônea das duas oposições: aquela da sincronia e da diacronia e aquela da estática e da dinâmica. O começo e o fim de de todo processo de mutação coexistem na sincronia e pertencem a dois subcódigos diferentes de uma só e mesma língua. Consequentemente, toda mudança somente pode ser compreendida e explicada em função do sistema que as sofre ou do papel que elas desempenham no interior desse sistema; inversamente, nenhuma língua pode receber uma descrição completa e adequada sem que se leve em conta 'as mudanças que estão se operando'. A proibição absoluta introduzida por Saussure de estudar simultaneamente as relações no tempo e as relações no sistema perde sua validade. As mudanças aparecem como dizendo respeito a uma sincronia dinâmica (JAKOBSON, 1973, p. 22). 
No que diz respeito ao primeiro ponto, de fato, Saussure, sustenta claramente que a mudança linguística ocorre acidentalmente, seu ponto de vista sendo marcadamente não teleológico ${ }^{2}$. Contudo, no tocante ao segundo ponto, a ideia de acordo com a qual sistema e história em Saussure seriam dois elementos que se opõem, não parece proceder quando de uma leitura mais atenta do CLG.

Se por um lado, "o deslocamento de um sistema se faz sob a ação de eventos que não somente lhe são estranhos, mas que são isolados e não formam sistema entre eles" (SAUSSURE, 1972, p. 134), por outro, Saussure, comparando a língua a uma partida de xadrez, observa que, embora "cada jogada de xadrez coloca em movimento uma peça apenas", ela, ao mesmo tempo, "tem repercussão sobre o sistema" (SAUSSURE, 1972, p. 126). Tullio de Mauro, observa, a este propósito, que Saussure na conclusão de seu ensaio sobre os adjetivos do tipo caecus é bastante claro, mas que o próprio CLG não deixa dúvidas a esse respeito. Para o autor, a leitura dessa obra deixa claro que, segundo ela,

as mudanças nascem acidentalmente, sem finalidade, elas atingem cegamente uma entidade ou uma classe de entidades e não com o objetivo de passar a uma organização diferente do sistema; mas justamente porque a língua, graças à analogia, tende ao sistema, as mudanças "condicionam" o sistema (DE MAURO, 1972[1967], p. 454).

de modo que, em Saussure, "a exclusão do teleologismo é tão forte quanto a afirmação da sistematicidade das consequências de toda mudança" (ibid.).

A leitura de Tullio de Mauro se dá num contexto de recepção muito diferente daquele de Jakobson; esse contexto é marcado não pela fixação de interpretações, mas, ao contrário, pela suspensão de interpretações com vistas a aprofundamentos, desta vez, amparado pelas fontes manuscritas, sem que se proceda ainda a uma oposição radical entre estas e o $C L G^{3}$. A reação do filólogo italiano, assim, em face dessa suposta contradição de Saussure, que consiste em ora afirmar que a relação entre sistema e história é tão estreita que seria difícil separá-los, e ora afirmar que a oposição entre sincronia e diacronia é absoluta, não é a de dissimulação, mas, antes, de tentativa real de compreensão do problema.

Para De Mauro, a contradição é apenas aparente. Ele observa que Saussure faz no CLG uma importante distinção entre matéria e objeto. Assim, lemos no segundo capítulo da Introdução dessa obra, intitulado "Matéria e tarefa da linguística: suas relações com as ciências conexas" o seguinte: "a matéria da linguística é constituída primeiramente por todas as manifestações da linguagem humana" (SAUSSURE, 1972, p. 20). Em relação ao objeto, como sabemos, para Saussure, se em outras ciências, opera-se com objetos dados previamente, podendo estes ser estudados de diferentes pontos de vista, em linguística nada ocorre de parecido: "longe de supor que o objeto precede o ponto de vista, diríamos que é o ponto de vista que precede o objeto" (SAUSSURE, 1972 p. 23). A separação entre sincronia e diacronia é, segundo Tullio de Mauro, uma separação de pontos de vista; ela não concerne à matéria: "ela tem um caráter metodológico, concerne ao pesquisador e seu objeto [...] e não

\footnotetext{
2 Sobre esse ponto, Fontaine, entre outros autores, observa que a reintrodução por Jakobson nos estudos linguísticos de uma visão teleológica da mudança representa, na verdade, uma volta à tradição naturalista e romântica em linguística, cujo representante mais entusiasta foi August Schleicher. Apenas, diferentemente de Schleicher, Jakobson não viu a mudança de forma pessimista, como corrupção, mas, ao contrário, como um processo que se realiza em função de um bem: assegurar a comunicação (cf. FONTAINE, 1978, p. 49).

3 Essa oposição radical somente ocorrerá de forma sistemática a partir do final dos anos 1990, com Eisuke Komatsu, e, sobretudo, Simon Bouquet, para quem os editores do CLG teriam falseado o suposto "verdadeiro" pensamento saussuriano (cf. CRUZ, 2016).
}

Revista do GELNE, Natal/RN, Vol. 19 - Número Especial/Dossiê: p. 248-259. 2017 
ao conjunto de coisas de que trata o pesquisador, sua matéria (DE MAURO, 1972[1967] in SAUSSURE, 1972, p. 453, ênfase de Tullio de Mauro). Ele observa que um pesquisador encontra-se sempre diante de um estado e que Saussure sabe e, mais do que isso, afirma explicitamente, numa passagem já referida aqui neste artigo, que "a cada instante ela [a linguagem] implica ao mesmo tempo um sistema estabelecido e uma evolução; a cada momento, ela é uma instituição atual e um produto passado" e se "parece à primeira vista muito simples distinguir entre esse sistema e sua história, entre aquilo que ele é e aquilo que ele foi; na realidade, a relação que une essas duas coisas é tão estreita que é difícil separá-las" (SAUSSURE, 1972, p. 24). É interessante, contudo, observar, que De Mauro não comenta a outra passagem do CLG que citamos mais acima, em que se faz a seguinte pergunta: "se todos os fatos de sincronia associativa e sintagmática têm sua história, como manter a distinção absoluta entre a diacronia e a sincronia?” (SAUSSURE, 1972, p. 194). Trata-se aí de uma passagem em que Saussure parece relativizar o caráter radical da separação entre sincronia e diacronia, caráter esse fundamental, contudo, em seu projeto de uma linguística geral, já que permitia resolver um problema que remonta à origem mesma do projeto de constituição de um domínio de estudos linguísticos autônomo e científico com Franz Bopp e que diz respeito à questão do tempo ${ }^{4}$. Ao que parece, a "matéria", ou antes, a realidade não deixa de incidir, de algum modo, sobre o "objeto", causando dificuldades a Saussure, que, nos parece, jamais foram superadas. $\mathrm{E}$ aqui entramos na discussão propriamente dita deste artigo $^{5}$, que procura, lembrando, abordar dois aspectos do problema em torno da separação entre sincronia e diacronia. O primeiro deles, como vimos, concerne ao objeto de estudo de cada um desses dois pontos de vista. Saussure, como veremos, parece hesitar em relação a esse ponto; o segundo é engendrado por essa discussão e concerne ao suposto caráter radical dessa separação, ponto este que é, igualmente, como veremos, objeto de hesitação em Saussure.

\section{Sincronia e diacronia: dois pontos de vista, dois objetos?}

Numa primeira abordagem, temos a impressão de que o ponto de vista sincrônico e o ponto de vista diacrônico estudam ambos o mesmo objeto, a língua, a partir de perspectivas distintas. O primeiro estuda a língua considerada num estado, e o segundo estuda a língua ao longo do tempo. É o que se pode concluir se se considera o seguinte esquema, retirado do capítulo III da primeira parte do CLG:

$$
\text { linguagem }\left\{\begin{array}{l}
\text { língua } \\
\text { fala }
\end{array}\right.
$$

${ }^{4}$ Cf., em particular, Chiss (1978).

${ }^{5}$ Alguns pontos da discussão que faremos a seguir retomam desenvolvimentos anteriores ( $c f$. CRUZ, 2016).

Revista do GELNE, Natal/RN, Vol. 19 - Número Especial/Dossiê: p. 248-259. 2017 
E se se considera também a seguinte afirmação retirada desse mesmo capítulo: "para melhor marcar esta oposição e esse cruzamento das duas ordens de fenômenos relativas ao mesmo objeto, preferimos falar de linguística sincrônica e de linguística diacrônica" (SAUSSURE, 1972, p. 117, ênfase nossa), pode-se concluir que ambos os pontos de vista, sincrônico e diacrônico, estudam a língua.

Lemos, contudo, ainda nesse mesmo capítulo, que "se ele [o linguista] se coloca na perspectiva diacrônica, não é mais a língua que ele percebe, mas uma série de eventos que a modificam" (SAUSSURE, 1972, p. 128). Para Saussure, a essência da língua é sua capacidade de significar. A língua, ele afirma, "é um sistema de signos em que somente há de essencial a união do sentido e da imagem acústica e em que as duas partes do signo são igualmente psíquicas" (SAUSSURE, 1972, p. 32). Lemos em outro lugar no CLG: "ela [a língua] é o conjunto dos hábitos linguísticos que permitem a um sujeito compreender e se fazer compreender" (SAUSSURE, 1972, p. 112).

Essa instância da linguagem humana que concerne a comunicação e que para Saussure é a língua, é estranha à diacronia; ela não diz respeito senão à sincronia. Essa ideia aparece de forma clara no texto intitulado "Da essência dupla da linguagem" em que se lê o seguinte: "o fenômeno primordial da linguagem é a associação de um pensamento a um signo; $e$ é justamente esse fato primordial que esta suprimido na transmissão do signo" (SAUSSURE, 2002, p. 47, ênfase nossa). Lemos mais abaixo nesse mesmo texto:

Pode-se entender por vida da linguagem primeiramente o fato de que a linguagem vive através do tempo, isto é, é suscetível de se transmitir. Esse fato é, se quisermos, um elemento vital da linguagem, porque não há nada na linguagem que não seja transmitido, mas ele é antes absolutamente estranho à linguagem.

- Ou SIGNO e sequência de tempo mas nada de IDEIA no signo. É o que se chama de fonética. - Ou SIGNO e IDEIA: mas, então, inversamente nada de sequência de tempo; necessidade de respeitar completamente o instante e unicamente o instante. É o domínio da morfologia, da sintaxe, da sinonímia, etc. (SAUSSURE, 2002, p. 53-54, ênfase nossa em negrito).

Ao que parece, esse texto é o primeiro em que Saussure estabelece claramente uma distinção entre aquilo que mais tarde ele chamará de ponto de vista sincrônico e ponto de vista diacrônico. Esse texto, que segundo Engler, foi escrito em 1891, é, ao que tudo indica, o texto ao qual Saussure se refere numa carta endereçada a Gaston Paris, datada de 30 de dezembro de 1891. Saussure a inicia apresentando um pedido de desculpas por não ter podido escrever antes: "eu estava infelizmente [...] muito atrasado preparando as conferências de abertura de meu curso. Depois, o assunto dessas conferências me conduziu a um trabalho inteiramente novo no qual eu, por mal, acabei me absorvendo" (DÉCIMO, 1994, p. 78). A ideia central desse trabalho é, então, assim resumida:

Eu acredito que não há morfologia (ou gramática) histórica e que reciprocamente não há fonética momentânea. O laço entre os estados de língua sucessivos se resumiria, se bem examinado, ao laço fonético; o laço entre os elementos de um mesmo estado, inversamente, ao laço morfológico, mesmo que se trate em aparência de fonemas sem valor significativo. Haveria oposição primordial e incompatibilidade entre a visão fonética da língua, que supõe "sucessão" e "abstração total do sentido" - e a visão morfológica (gramatical) que supõe "unidade de época" e "consideração do sentido, valor, emprego"... Eu tento desenvolver e justificar essa maneira de ver; é claro, todavia, que ela toca todas as questões primeiras e que é, consequentemente, muito difícil saber onde parar sua análise (DÉCIMO, 1994, p. 79).

O que parece caracterizar a dimensão diacrônica em Saussure não é unicamente o fator tempo, mas também e igualmente esse aspecto da linguagem humana que diz respeito 
exclusivamente aos sons. Inversamente, o que parece caracterizar a dimensão sincrônica não é, por sua vez, unicamente a exclusão do fator tempo, mas também e igualmente a consideração da linguagem humana em sua dimensão viva, isto é, a língua.

A distinção entre ambos os pontos de vista posta nesses mesmos termos não está, porém, ausente do CLG. Lemos, assim, nessa obra: "a primeira coisa que chama a atenção quando se estudam os fatos de língua, é que para o sujeito falante sua sucessão no tempo é inexistente" (SAUSSURE, 1972, p. 117). Sendo assim, “o linguista que pretende compreender esse estado deve fazer tábua rasa de tudo o que o produziu e ignorar a diacronia. Ele somente pode entrar na consciência dos sujeitos falantes suprimindo o passado" (SAUSSURE, 1972, p. 117). Quando do uso da língua, é a comunicação e somente a comunicação que importa. O apagamento da história é, nesse sentido, uma condição para que ela seja possível. Do mesmo modo que "seria absurdo desenhar um panorama dos Alpes considerando-o simultaneamente de diversos picos do Jura" também, quando se trata da língua, "não se pode nem descrevê-la, nem fixar normas para o uso sem que nos coloquemos num determinado estado" (SAUSSURE, 1972, p. 117).

Lemos, também, no CLG: "a sincronia não conhece senão uma perspectiva, aquela dos sujeitos falantes" (SAUSSURE, 1972,, p.128). A análise sincrônica, ou se preferirmos, a "análise subjetiva" consiste na "análise das unidades da língua feita a todos os instantes pelo sujeito falante" (SAUSSURE, 1972, p.251). Trata-se de "observar o que se passa nas línguas de hoje, na linguagem de todos os dias" (SAUSSURE, 1972, p. 252), trata-se, em uma palavra, de observar o que se passa na "língua viva" (1972, p. 253). É por essa razão que "o estudo sincrônico não tem como objeto tudo o que é simultâneo, mas somente o conjunto de fatos correspondentes a cada língua" (1972, p. 128). Trata-se de abordar as relações entre os termos coexistentes tal qual eles são percebidos "por uma mesma consciência coletiva" (1972, p. 140).

A dimensão diacrônica, por sua vez, procura sobrepor uma série de estados para, a partir daí, depreender os fenômenos que fizeram com que a língua passasse de um estado a outro. Esses fenômenos nada têm a ver com o sentido: "as mudanças se produzem fora de toda intenção. Ao contrário o fato de sincronia é sempre significativo” (SAUSSURE, 1972, p. 122). À diacronia, interessa em particular a fonética. Assim, lemos no CLG:

a fonética e toda a fonética é o primeiro objeto da linguística diacrônica; com efeito a evolução dos sons é incompatível com a noção de estado; comparar fonemas ou grupo de fonemas com o que eles foram anteriormente significa estabelecer uma diacronia. A época precedente pode ser mais ou menos próxima; mas quando uma e outra se confundem, a fonética cessa de intervir; resta apenas a descrição dos sons de um estado de língua, e cabe à fonologia fazê-lo.

O caráter diacrônico da fonética concorda muito bem com o princípio de que nada do que é fonético é significativo ou gramatical, no sentido amplo [...]. Para fazer a história dos sons de uma palavra, pode-se ignorar seu sentido e considerar somente seu invólucro material, cortar frações fônicas sem se perguntar se elas possuem uma significação; procuraremos saber, por exemplo, o que se torna em grego ático um grupo como -ewo-, que nada significa (SAUSSURE, 1972, p. 194).

Portanto, se o estudo sincrônico, como acabamos de ver, tem como objeto o conjunto de fatos correspondentes a uma mesma língua, na medida em que se trata aí de abordar as relações entre termos percebidos por uma mesma consciência coletiva, o estudo diacrônico, ao contrário, "não somente não necessita, mas rechaça tal especialização; os termos que ele considera não pertencem necessariamente a uma mesma língua (compare o indo-europeu

Revista do GELNE, Natal/RN, Vol. 19 - Número Especial/Dossiê: p. 248-259. 2017 
*esti, o grego ésti, o alemão ist, o francês est)" (SAUSSURE, 1972, p. 129). Neste caso, trata-se de estudar os termos em sua relação de sucessão, "não percebidos por uma mesma consciência coletiva" (1972, p. 129), a dimensão da comunicação sendo, portanto, estranha ao ponto de vista diacrônico.

\section{Sincronia e diacronia: de uma separação absoluta e fundamental a uma relação de oposição fluida e hesitante?}

A separação entre sincronia e diacronia é, para Saussure, uma condição fundamental para a possibilidade de uma ciência da linguagem. Nas "Notas para um artigo sobre Whitney", texto escrito em 1894 e publicado no tomo 2 da edição crítica de Engler (1974) e republicada nos Escritos, lemos: "só há 'língua' e ciência da linguagem com a condição inicial que se faça abstração do que precedeu, do que liga as épocas entre si" (SAUSSURE, 2002, p. 217); isso porque "não há nenhum tipo de generalização possível se se continua a considerar cada produto em sua gênese e em sua essência ao mesmo tempo" (2002, p. 217).

Saussure, contudo, mais tarde, na ocasião do segundo curso de linguística geral (1908-1909), faz uma objeção a respeito de sua afirmação, presente na carta supracitada endereçada a Gaston Paris, segundo a qual, "não há morfologia (ou gramática) histórica". Assim, Saussure afirma, de acordo com o caderno de Albert Riedlinger relativo ao segundo curso:

Concordar-se-á muito facilmente que o que é fonético não é gramatical, de modo que se o campo diacrônico compreendesse unicamente a fonética, a oposição que estabelecemos entre as matérias que entram no campo sincrônico e no campo diacrônico seria imediatamente evidente; de um lado teríamos: diacrônico $=$ não gramatical e, de outro, sincrônico = gramatical. Mas é claro que desde o início perguntar-se-á se não há outra história a fazer para além daquela dos sons e se não caímos novamente em assuntos gramaticais. Assim, haverá o fato de que uma palavra mudou de significação ou que formas como aquelas do dual entram pouco a pouco em desuso em uma língua, ou o fato de desenvolvimento analógico. Em resumo, tudo o que pertence à sincronia não possui sua história, os sintagmas e as associações? A partir do momento em que se sai da fonética pura, é na verdade muito mais difícil traçar o limite ou afirmar uma oposição radical. Eis aí o ponto da divisão geral mais difícil, mas não podemos insistir sem que nos lancemos em considerações que são delicadas (SAUSSURE, 1997, p. 67).

Essa hesitação pode ser igualmente percebida na leitura do $C L G$, em que se lê:

Se a evolução da língua se reduzisse àquela dos sons, a oposição dos objetos próprios às duas partes da linguística seria imediatamente evidente: veríamos claramente que diacrônico equivale a não-gramatical, como sincrônico à gramatical.

Mas será que são somente os sons que se transformam com o tempo? As palavras mudam de significação, as categorias gramaticais evoluem; vemos aquelas que desaparecem com as formas que serviam para exprimi-las (por exemplo o dual em latim). E se todos os fatos de sincronia associativa e sintagmática possuem sua história, como manter a distinção absoluta entre a diacronia e a sincronia? Isso se torna muito difícil assim que se sai da fonética (SAUSSURE, 1972, p. 194).

Lemos um pouco mais abaixo: 
Se, portanto, a fonética intervém na maioria das vezes por um lado qualquer na evolução, ela não pode explicá-la totalmente; o fato fonético uma vez eliminado, encontra-se um resíduo que parece justificar a ideia 'de uma história da gramática'; eis aí a verdadeira dificuldade; a distinção - que deve ser mantida - entre o diacrônico e o sincrônico demandaria explicações delicadas, incompatíveis com o quadro deste curso (SAUSSURE, 1972, p. 197).

Como se pode ver, essa questão que "toca todas as questões primeiras" (DÉCIMO, 1994, p. 79), está longe de ser ponto pacífico em Saussure, de modo que a fixação de uma interpretação que pretenda fazer dos domínios sincrônico e diacrônico dois domínios absolutamente separados, parece resistir ao próprio CLG.

A separação entre os pontos de vista sincrônico e diacrônico deve ser lida à luz da história. É importante que se reconstitua o contexto de emergência das ideias de Saussure em torno da linguística geral. O fim do século XIX é marcado pelo retorno da dimensão humana da linguagem, apagada pelos estudos que se desenvolvem a partir da tradição comparatista iniciada por Franz Bopp. Não há espaço aqui para uma historicização. Contentemo-nos simplesmente em afirmar que a hipótese do indo-europeu, que surge no final do século XVIII, e também a emergência com Bopp do projeto de um domínio de estudos linguísticos autônomo e científico, tudo isso conduziu a um gradual apagamento da dimensão do sentido dos estudos linguísticos e uma particular atenção à dimensão dos sons, cuja evolução atestava uma regularidade quase matemática, o que, inicialmente, não apenas justificava a inscrição da linguística no domínio das ciências naturais, mas, sobretudo, parecia assegurar cientificidade à jovem ciência. A linguística, contudo, terminou por se reduzir praticamente ao estudo da evolução dos sons em seu aspecto fisiológico, excluindo o sentido e, assim, a dimensão viva da linguagem. Uma citação de Michel Bréal é emblemática e mostra bem o o clima intelectual deste final do século XIX, que entende que o objeto de estudo da linguística transcende o mero aspecto histórico-fisiológico. Assim, ele afirma o seguinte em seu livro intitulado Essais de sémantique: sciences de signification:

Os livros de gramática comparada se sucedem para o uso dos estudantes, para o uso do grande público, mas não me parece que aquilo que é oferecido seja de fato o que se deveria dar. Para aquele que sabe interrogá-la, a linguagem está cheia de lições, pois há muitos séculos a humanidade nela deposita as aquisições de sua vida material e moral; mas, ainda, é preciso tomá-la pelo lado em que ela fala à inteligência. Se se limita às mudanças de vogais e de consoantes, reduz-se esse estudo às proporções de um ramo secundário da acústica e da fisiologia; se se contenta em enumerar as perdas sofridas pelo mecanismo gramatical, tem-se a ilusão de um edifício em ruinas (BRÉAL, 1897, p.1-2, ênfase nossa).

\section{Conclusão}

Como vimos nesta breve reflexão, Jakobson considera o CLG não como um compêndio, mas como uma obra que apresentaria "os começos movimentados de uma edificação nova e inovadora", que não poderia estar isenta de contradições. Isso não autoriza, segundo ele, que se condene em bloco seus valores fundamentais. Quanto às suas contradições, estas deveriam ser discernidas e não dissimuladas. Procuramos aqui mostrar que, apesar dessa apreciação do $C L G$, e do compromisso em não dissimular as contradições, Jakobson não deixou de fixar interpretações sobre pontos fundamentais que, no entanto, para o próprio Saussure, ainda eram obscuros e demandavam explicações. É o caso do problema girando em torno da separação entre sincronia e diacronia, cujo suposto caráter radical foi

Revista do GELNE, Natal/RN, Vol. 19 - Número Especial/Dossiê: p. 248-259. 2017 
fortemente criticado pelo linguista russo, que ignorou passagens importantes do CLG que, justamente, obstavam sua leitura.

Para Saussure, esse problema é oriundo, como vimos, de uma maneira de ver as coisas que "toca todas as questões primeiras". Jean-Louis Chiss já em 1978 - antes, portanto, da publicação da carta, referida aqui, que Saussure envia a Gaston Paris, ou do texto intitulado "Da essência dupla da linguagem" - aventou a hipótese de que "se Saussure define sincronia/diacronia como 'a segunda ramificação (depois de língua/fala), ele parece ter descoberto esta segunda bifurcação da linguística antes da 'primeira' (CHISS, 1978, p. 101). Ainda de acordo com Chiss, "a distinção sincronia/diacronia aparece, mais que a oposição língua/fala, como o passo fundador no projeto saussuriano” (CHISS, 1978, p. 101).

Com efeito, trata-se aí, provavelmente, do mais importante pilar do edifício saussuriano. Para o linguista genebrino, o projeto de um domínio de estudos linguísticos autônomo e científico, lançado por Bopp em 1816, somente poderia se realizar quando da solução do problema da temporalidade. A linguística de Bopp e toda a tradição comparatista que a ele se seguiu insistiu no erro denunciado por Saussure de acreditar que, em matéria de linguagem, uma generalização qualquer fosse possível considerando-se cada produto em sua gênese e em sua essência ao mesmo tempo. A separação radical entre sincronia e diacronia foi a resposta de Saussure ao problema da temporalidade, o que teria, enfim, permitido a efetivação do projeto de uma linguística autônoma e científica. Saussure, contudo, hesita a respeito desse ponto fundamental em sua reflexão, e parece, de algum modo, relativizar o caráter radical da separação entre ambos os pontos de vista.

Atualmente assistimos, no vasto continente do saussurismo, à emergência de uma atitude que consiste na busca de respostas a problemas colocados pela linguística contemporânea advindas de novas interpretações da linguística saussuriana, baseadas, em especial, nos textos originais. Quisemos aqui, de nossa parte, mostrar que Saussure, em sua reação à linguística que se desenvolvia no século XIX, e na tentativa de, finalmente, efetivar o projeto de Bopp de fundação de uma ciência linguística, embora tivesse proposto um plano, não foi, ao final, levado aos destinos que ele pretendia. Apesar disso, nem sempre a linguística que se seguiu a Saussure procurou continuar efetivamente as pistas deixadas por ele. O que se viu foi, antes, o apontamento de erros de percurso, mesmo lá onde não havia caminho trilhado, mas apenas esboços extremamente conscientes dos tantos obstáculos que era preciso superar.

\section{Referências}

Bréal, Michel. (1897) Essai de sémantique : science des significations. Paris : Hachette et $C^{\text {ie }}$.

Chiss, Jean-Louis. (1978). "Synchronie/diachronie: méthodologie et théorie en linguistique" in Langages, no 49, p. 91-111.

Chiss, Jean-Louis; Puech, Christian (1999). Le langage et ses disciplines XIX ${ }^{e}-X^{e}$ siècles, Paris Bruxelles, De Boeck \& Larcier, Département Duculot.

Cruz, Marcio Alexandre (2016). "Por que (não) ler o Curso de linguística geral depois de um século? In: Faraco, Carlos Alberto (2016). O efeito Saussure. São Paulo: Parábola Editorial, p. 25-48. 
Décimo, Marc (1994), "Saussure à Paris”, Cabiers Ferdinand de Saussure 48, 75-90.

Fontaine, Jacqueline (1978). O círculo linguístico de Praga. São Paulo: Editora Cultrix.

Gadet, Françoise (1995). Jakobson sous le pavillon saussurien. In: Linx, p. 2-8, disponível em https://linx.revues.org/1238, consultado em 12 de julho de 2017.

Jakobson, Roman (1973). Essais de linguistique générale. Tome 2: Rapports internes et externes du langage. Paris: Les Éditions de Minuit.

Jakobson, Roman (1984[1942]). "La théorie saussurienne en rétrospection". In: Linguistics, 22, p. 161-196.

Mauro, Tullio de (1972[1967]). "Notes". In: Saussure, Ferdinand de (1972[1916]). Cours de linguistique générale publié par Charles Bally et Albert Sechehaye avec la collaboration de Albert Riedlinger, édition critique préparée par Tullio de Mauro, postface de Louis-Jean Calvet, Paris : Editions Payot \& Rivages. Édition critique originale italienne, 1967 ; notes et commentaires de T. de Mauro trad. par L.-J. Calvet, pp. 405-477.

Milano, Luiza; Flores, Valdir do Nascimento (2016). "O que ainda se pode dizer sobre uma herança?: Saussure e Jakobson”. In: Cruz, Marcio Alexandre; Piovezani, Carlos; Testenoire, Pierre-Yves (2016). Saussure, o texto e o discurso: cem anos de heranças e recepções. São Paulo: Parábola Editorial.

Puech, Christian (2005). "Lémergence de la notion de 'discours' en France et les destins du saussurisme", Langages, 159, pp. 93-110.

Saussure, Ferdinand de (1972[1916]). Cours de linguistique générale publié par Charles Bally et Albert Sechehaye avec la collaboration de Albert Riedlinger, édition critique préparée par Tullio de Mauro, postface de Louis-Jean Calvet, Paris : Editions Payot \& Rivages. Édition critique originale italienne, 1967 ; notes et commentaires de T. de Mauro trad. par L.-J. Calvet.

Saussure, Ferdinand de (1997). Deuxième cours de linguistique générale (1908-1909) d'après les cahiers d'Albert Riedlinger et Charles Patois/ Saussure's Second course of lectures on general linguistics (1908-1909) from the notebooks of Albert Riedlinger and Charles Patois. French texte edited by Eisuke Komatsu. English translation by George Wolf. Oxford, New York, Tokyo: Pergamon.

Saussure, Ferdinand de (2002). Écrits de linguistique générale. Texte établi et édité par Simon Bouquet et Rudolf Engler. Paris: Gallimard.

Sériot, Patrick (1999). Structure et totalité. Paris: PUF. 